\title{
Estimation of the Market Potential for Supersonic Airliners via Analysis of the Global Premium Ticket Market
}

\author{
Bernd Liebhardt ${ }^{1}$, Klaus Luetjens ${ }^{2}$, Volker Gollnick ${ }^{3}$ \\ Deutsches Zentrum für Luft- und Raumfahrt (DLR), Hamburg, Germany
}

\begin{abstract}
This study assesses the global market potential for supersonic airline transportation by evaluating worldwide premium ticket sales figures based on so-called marketing information data tapes (MIDTs). Origin-destination demand data were collected from an internet database and subjected to various processings and additions. After discussing factors of influence regarding market response, the final data files are used to estimate possible future demand for variously sized supersonic airliners.
\end{abstract}

$\begin{array}{ll}\text { LOS } & =\text { Length of stay } \\ \text { MIDT } & =\text { Marketing Information Data Tape } \\ O / D & =\text { Origin-destination (city pair) } \\ S S T & =\text { Supersonic transport }\end{array}$

\section{Nomenclature}

I. Introduction and Background

QINCE the ending of Concorde's airline service in 2003, there is no more civil supersonic flight. For the first time

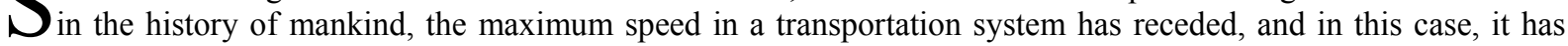
dropped dramatically. Compared to Mach 2 in Concorde, the Cessna Citation X's maximum speed of Mach 0.92 appears ridiculously low.

This is why many think the return to supersonic is overdue. Technology is obviously not the problem since the Anglo-French Concorde consortium and Russian Tupolev demonstrated being able to bring a Supersonic Transport (SST) to reality more than 40 years ago. But the lacking economic success of said programs and today's more difficult market environment raise suspicion that the demand for super-fast transportation might have ever been too limited for supporting large supersonic airplanes.

Despite recent research, drafting, and design of various civil supersonic aircraft ${ }^{\mathbf{1 , 2 , 3 , 4}}$ and despite ever-returning optimistic calls for the next-generation SST, the authors know of no scientific study that has managed to assess the global market for supersonic airline transportation in detail in order to find the proper design requirements (size, range, speed) of future SSTs. One former airline market analyst complained that aircraft specifications in SST programs were usually determined by enthusiasts of speed before commissioning the commercial analysis department to "make the figures fit", instead of listening to the market experts in the first place 5 .

A new kind of well-founded supersonic transport market assessment has now come into reach with the advent of commercial internet-based platforms that provide fast access to so-called marketing information data tapes (MIDTs).

\section{Demand Data Compilation}

MIDTs are aggregated and anonymous booking data from the Global Distribution Systems (GDS) of airline tickets, providing important market and competition information regarding traffic flows, market shares, and booking characteristics. They represent the core of the data base used ${ }^{6}$, to be supplemented and adjusted by several sources including internet booking engines, governmental data, the IATA Billing and Settlement Plan (BSP), and others. That way, the supplier claims to provide accurate origin-destination $(\mathrm{O} / \mathrm{D})$ demand figures for the whole global airline traffic, unlike the time-honored Official Airline Guide (OAG) that can only display seat capacities on given flight legs.

\footnotetext{
${ }^{1}$ Research Associate; Air Transportation Systems, Blohmstrasse 18, 21079 D-Hamburg; Non-AIAA Member.

${ }^{2}$ Head of Department; Air Transportation Systems, Blohmstrasse 18, 21079 D-Hamburg; Non-AIAA Member.

${ }^{3}$ Director of Institute; Air Transportation Systems, Blohmstrasse 18, 21079 D-Hamburg; AIAA Member.
} 
The web dialogue mentioned provides display of past ticket sale characteristics for specific location pairs (each can be airports, countries or regions) in a given timeframe (down to a month), starting in 2002.

The output data (see Figure 1) comprise

- origin and destination (airport code, city name, country),

- the operating airline,

- the cabin class,

- the passenger count,

- the total revenue,

- the average fare, and

- year and month of the flight.

\begin{tabular}{|c|c|c|c|c|c|c|c|c|c|c|c|c|}
\hline Origin & OriginName & OriginCountry & Destin. & Destin.Name & Destin.Country & Oper.AL & CabinClass & Pax & Rev.(USD) & AvgFare(USD) & Year & Month \\
\hline AMD & Ahmedabad & India & GIG & Rio De Janeiro & Brazil & EK & Business & 3 & 10140 & 3380 & 2009 & 1 \\
\hline ALA & Almaty & Kazakstan & EZE & Buenos Aires & Argentina & $\mathrm{LH}$ & Business & 1 & 4066 & 4066 & 2009 & 1 \\
\hline ANF & Antofagasta & Chile & NGS & Nagasaki & Japan & AA & Business & 1 & 5770 & 5770 & 2009 & 1 \\
\hline ASB & Ashgabat & Turkmenistan & EZE & Buenos Aires & Argentina & $\mathrm{LH}$ & First & 1 & 4990 & 4990 & 2009 & 1 \\
\hline TSE & Astana & Kazakstan & SSA & Salvador & Brazil & JJ & Business & 1 & 4227 & 4227 & 2009 & 1 \\
\hline ASU & Asuncion & Paraguay & TPE & Taipei & Taiwan & UA & First & 4 & 18384 & 4596 & 2009 & 1 \\
\hline ASU & Asuncion & Paraguay & TPE & Taipei & Taiwan & UA & Business & 11 & 35464 & 3224 & 2009 & 1 \\
\hline ASU & Asuncion & Paraguay & NRT & Tokyo & Japan & JL & First & 1 & 3660 & 3660 & 2009 & 1 \\
\hline ASU & Asuncion & Paraguay & NRT & Tokyo & Japan & JL & Business & 11 & 40201 & 3655 & 2009 & 1 \\
\hline ASU & Asuncion & Paraguay & NRT & Tokyo & Japan & $\mathrm{NH}$ & Business & 6 & 19058 & 3176 & 2009 & 1 \\
\hline$\Delta S U$ & Asuncian & Daracumav & NDT & Takun & lanon & $1 \Delta$ & Rusinose & 3 & 15387 & 5129 & 2nחa & 1 \\
\hline
\end{tabular}

Figure 1. “O\&D Market Details" query sample

Additionally, the platform provides information on flight distance and the passengers' average length of stay at their respective destination.

Before starting with data queries, the basic assumption was made that passengers of future supersonic airliners will recruit almost exclusively from the premium cabins (business \& first class) of regular airlines flying the respective routes since tickets for future supersonic airliners will likely be particularly expensive because of high fuel consumption. Regular economy class passengers are expected to be highly price sensitive ${ }^{6}$ and hence unresponsive to fast, costly travel, in contrast to business travellers that are very sensitive to service level changes.

Also, it was supposed that demand for supersonic travel will predominantly exist on long haul or intercontinental distances, respectively, since the time savings will only be significant on such routes.

In the following, the first steps towards the acquisition of the final data sets are listed:

- All intercontinental O/D demand (connecting two of the following regions: Africa, Asia, the Caribbean, Central America, Europe, the Middle East, North America, Oceania, and South America) in the premium classes (discount business, business, discount first, first) of 2002 to 2009 was retrieved.

- Specific intra-continental long haul O/D demand was added, encompassing the most important city pairs of Africa, Asia, North America, and South America.

Thus, more than 20 million data sets were made available comprising the whole global long-haul premium ticket market from 2002 to 2009.

In order to further condense relevant information, subsequent assumptions were made:

- Demand numbers regarding different airports serving the same city (e. g. John F. Kennedy, Newark, and La Guardia for New York, or Domodedovo, Sheremetyevo, and Vnukovo for Moscow) can be combined to a city's demand, since passengers will not mind changing from their preferred airports.

- The price difference between airlines and between premium cabin classes is negligible. The mean premium fare will sufficiently reflect the willingness to pay for a premium level of service (i.e. faster travel) and therefore the percentage of passengers willing to transfer to a supersonic airplane.

- O/D pairs flown on by less than 2,000 premium passengers yearly (which translates to about 40 passengers per week) will never be able to justify SST service. Thus, all corresponding city pairs were eliminated from the assessment.

Finally, between 2,200 and 3,800 O/D market data sets fulfilling all previous requirements were found for the respective years from 2002 to 2009. To these were added correspondingly (compare Figure 2)

- the stage lengths, having been queried for all scheduled non-stop flights worldwide previously; great circle distances were added manually where no data was available;

- the yield, being calculated by dividing the average fare by the distance 
- the variation from the expected yield, the latter being described by a trend line of yield over distance that was calculated using all data sets of the corresponding year;

- the average length of stay (LOS);

- the variation from the expected LOS, the latter being described by a trend line of LOS over distance that was calculated using all data sets of the corresponding year; and

- the time difference between origin and destination.

A sample of the data generated is shown in Figure 2.

\begin{tabular}{|c|c|c|c|c|c|c|c|c|c|c|}
\hline Origin & Destination & Pax & $\begin{array}{c}\text { Revenue } \\
\text { (USD) }\end{array}$ & $\begin{array}{l}\text { Dist. } \\
\text { (km) }\end{array}$ & $\begin{array}{c}\text { Avg. Fare } \\
\text { (USD) }\end{array}$ & $\begin{array}{l}\text { Avg. Fare } \\
\text { /km (Yield) }\end{array}$ & $\begin{array}{l}\text { Var. from } \\
\text { Exp. Yield }\end{array}$ & $\begin{array}{l}\text { Avg. } \\
\operatorname{LOS} \text { (d) }\end{array}$ & $\begin{array}{l}\text { Var. from } \\
\text { Exp. LOS }\end{array}$ & $\begin{array}{c}\text { Time } \\
\text { Diff. }\end{array}$ \\
\hline London & New York & 254.816 & 559.921 .595 & 5.592 & 2.197 & 0,393 & $39 \%$ & 5,2 & $-18 \%$ & -5 \\
\hline New York & London & 257.033 & 559.633 .114 & 5.592 & 2.177 & 0,389 & $37 \%$ & 4,8 & $-23 \%$ & 5 \\
\hline Los Angeles & New York & 196.361 & 202.000 .079 & 3.978 & 1.029 & 0,259 & $-12 \%$ & 3,7 & $-32 \%$ & 3 \\
\hline New York & Los Angeles & 192.097 & 196.233 .273 & 3.978 & 1.022 & 0,257 & $-13 \%$ & 3,4 & $-38 \%$ & -3 \\
\hline Paris & New York & 76.146 & 187.872 .730 & 5.863 & 2.467 & 0,421 & $49 \%$ & 5,1 & $-21 \%$ & -6 \\
\hline New York & Paris & 74.039 & 180.341 .634 & 5.863 & 2.436 & 0,415 & $48 \%$ & 5,6 & $-12 \%$ & 6 \\
\hline Hong Kong & London & 72.503 & 157.351 .053 & 9.648 & 2.170 & 0,225 & $-12 \%$ & 7,8 & $-6 \%$ & -8 \\
\hline Los Angeles & London & 60.088 & 155.684 .584 & 8.769 & 2.591 & 0,295 & $13 \%$ & 7,5 & $-5 \%$ & 8 \\
\hline London & Hong Kong & 71.052 & 153.219 .487 & 9.648 & 2.156 & 0,224 & $-13 \%$ & 8,0 & $-4 \%$ & 8 \\
\hline Duhai & I ondon & 86124 & 151789324 & 5502 & 1762 & 0320 & $13 \%$ & 64 & $3 \%$ & $=4$ \\
\hline
\end{tabular}

Figure 2. Intermediate data sample (year 2009, sorted by revenue)

These intermediate data represent the most popular connections of global long-range, premium-class airline transportation that hence are assumed to bear the best opportunities for supersonic airline service. Also, these data are considered fact and the starting point of hypothetical assessment.

\section{Intermission: Implications of the Supersonic Overland Flight Ban}

As an object in the atmosphere travels faster than the speed of sound, it will trail detonation shocks that are perceived as sudden bangs in some distance (the bang noise increasing with the object's mass and decreasing with its length). This sound, usually called "sonic boom", is thought to be a pivotal reason for supersonic civil flight not having been able to make a sustained breakthrough to this day.

When the strength of Concorde's sonic boom became commonly known, governments of all industrial countries rushed to ban supersonic flight over land. Since then, most countries do not allow the boom to reach the ground. (This can be achieved by flying only little faster than Mach 1 at cruise altitude, whereat aerodynamic drag in this "transonic" speed regime is particularly high). The U.S. interdicted supersonic overland flight entirely (Federal Aviation Regulations (FAR) 91.817). Given that these bans remain in effect, SSTs will have to cruise over water predominantly in order to make operational and economic sense.

Various efforts have been and still are being undertaken both to soften the boom with the help of changes to the airframe layout and to predict sonic boom strength ${ }^{7,8}$ as well as to define acceptable sonic boom levels ${ }^{9}$. In the wake of NASA's High Speed Research (HSR) initiative, the focus of the boom abatement works traversed from SSTs to smaller, so-called supersonic business jets (SSBJs) since it was found impossible to reshape commercial transportsize aircraft in order to obtain acceptable noise levels ${ }^{\mathbf{1 0}}$.

Yet, none of the proceedings have either prompted the ICAO to propose new regulations (this is planned for 2016 at the earliest ${ }^{11}$ ), nor have they agreed on a preferential low-boom technology, nor have they spawned the ability to guarantee certain maximum noise levels independently from atmospheric interferences. Moreover, reshaping the airframe for the sake of muted booms is known to cause additional drag. There is a certain risk of governments and societies rejecting a low-boom aircraft once they recognize the inverse correlation of sonic boom strength and fuel efficiency or atmospheric emissions, respectively.

Returning to our topic:

In order to allow for assessing the SST market for the verisimilar case of persisting restrictions, all city pairs need to be valued regarding their aptitude for supersonic transportation, meaning that at best, there will be only water between them.

Looking at exemplary routes of important city pairs, it was often found possible to achieve high supersonic cruise percentages with the help of relatively small detours around land masses. For instance, about $90 \%$ of the cruise distance can be preserved for supersonic speed on the Dubai - Singapore route when going round southern India and Sri Lanka, whilst only adding about 5\% to the total distance (see Figure 3). 


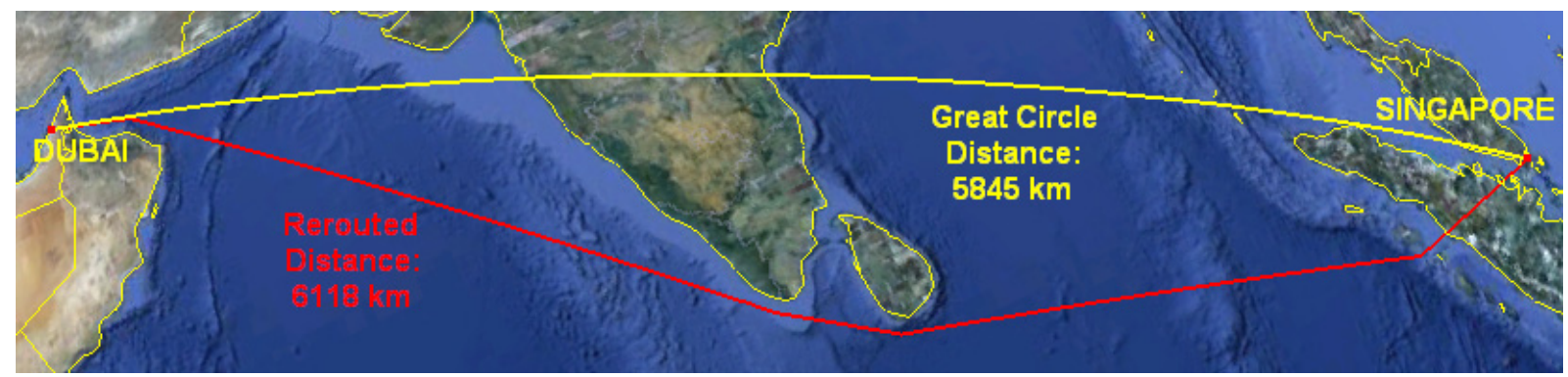

Figure 3. Direct and rerouted flight paths between Dubai and Singapore (credit: Google Earth)

Thus, flight time optimized routes for the 400 most important O/Ds of 2009 in terms of revenue were sketched; refuelling airports were included in case the distance exceeded a certain figure. The corresponding data sets were expanded with the following information: optional refuelling airports, rerouted distance, detour percentage relative to the great circle distance, and assumed supersonic cruise percentage.

When examining said routes, three quarters of them were found to possibly have supersonic cruise percentages of $80 \%$ and more, while only one sixth of the latter require detours of more than $10 \%$ regarding distance. We hold this to be a strong indication that the market for supersonic transportation will by no means disappear entirely in case the supersonic overland flight bans remain effective.

\section{Demand Data Extrapolation}

In order to estimate future demand, the collected data had to be extrapolated. Examining the numbers gained (and assuming that the 2000+ most important passenger data sets will represent the whole market sufficiently), the premium ticket market proved very volatile in recent years (see Figure 4). Demand remained static after the shock of the September 11 terrorist attacks of 2001 for one year before skyrocketing toward the world financial crisis of 2008, more than doubling up regarding revenue and passenger count. Afterward, the market took a sharp turn with passenger numbers dropping more than 40\% and revenue dropping more than 30\% between 2007 and 2009.

Because of this unsteadiness, it did not appear reasonable to extrapolate past demand developments into the future. Thus, air travel growth numbers for specific world regions forecasted by the Boeing Corporation ${ }^{\mathbf{1 2}}$ were applied (5.1\% yearly increase on average) in order to calculate future passenger numbers for the city pairs collected. 2009 data were used as a basis for extrapolation.

The final data files contain the premium travel demand of the 1365 most important city pairs for an arbitrary date in the foreseeable future.

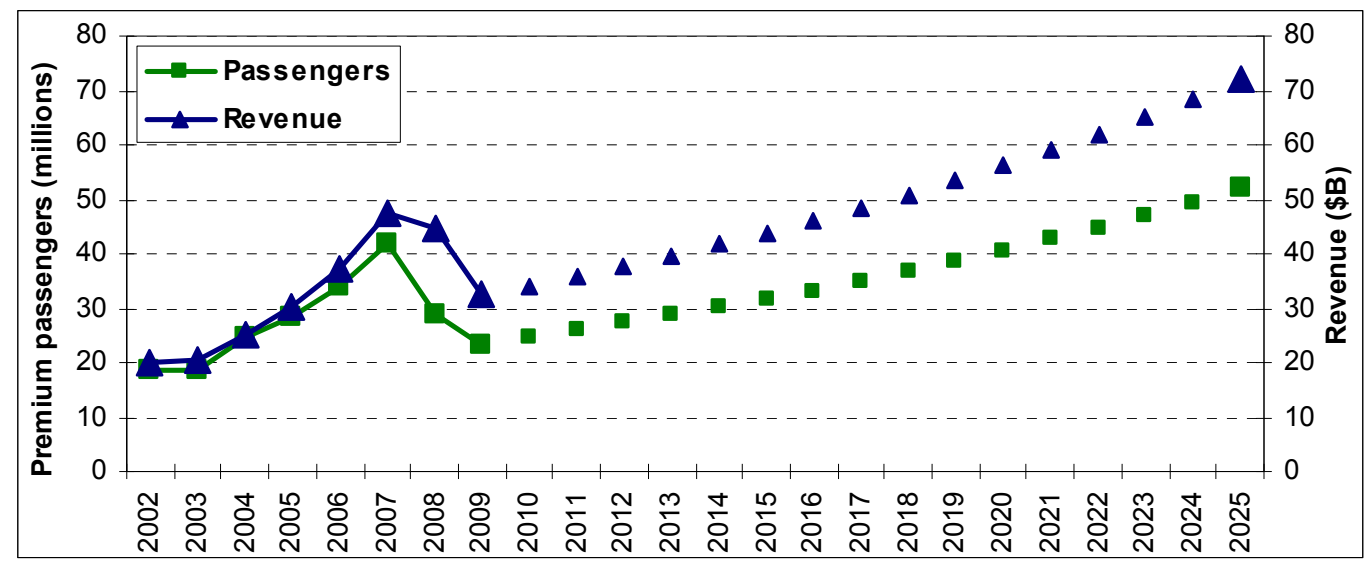

Figure 4. Past and future development of the premium airline travel market, 2002-2025

\section{Factors of Influence in SST Market Assessment}

In order to translate premium passenger numbers on specific O/Ds into accurate figures for global SST aircraft demand, several important factors of influence have to be taken into account. These are discussed subsequently. 


\section{A. Ticket price}

The price of an SST ticket is going to have major impact on the aircraft's market success. The demand for supersonic flight will diminish as its cost increases.

A rough in-house calculation indicated that the price of an SST ticket will possibly be in the dimension of business class fares, assuming high aircraft utilization. Yet, a more accurate cost model has to be developed in order to improve the demand modelling quality. For the time being, cost can be factored in with the help of the "variation from expected yield" figure. The higher the yield, the more passengers will probably consider changing to an SST.

\section{B. Time gain}

The paramount purpose of supersonic travel is saving time - the more, the better. This means that longer distances are basically preferential for SST service as the absolute time gain will be greater. Even if the distance requires refuelling stops, an SST will still be a lot faster than any other current means of transportation.

\section{Flight scheduling and time difference}

However, absolute time gain does not directly translate into a competitive advantage for a passenger travelling business. As distances increase, so does the time difference in general. Those two factors, in combination with speed, have a crucial impact on the possible schedule and hence on the benefit of an SST journey.

What if, for instance, an SST flight can only be scheduled to either arrive in the evening, after the working hours, or in the morning, after having had only little time for recreation (which is the case for a 4,000 nm flight 6 time zones eastward, e. g. Miami to Paris, see Figure 5)? Many passengers might prefer an evening flight and a night's sleep in a subsonic airplane. In this case, the sense of an SST journey is at least doubtful.

The benefits of all combinations regarding time difference and distance have to be valued and factored in subsequently when assessing the time benefit and the sense of SST service on specific routes.

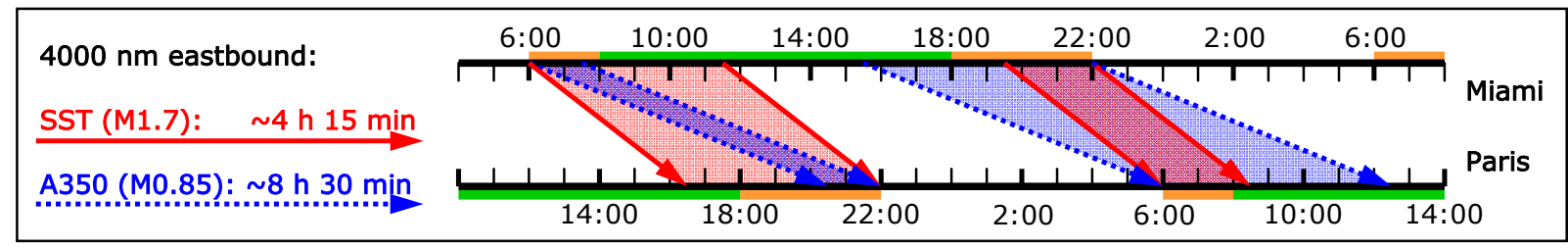

Figure 5. Flight scheduling for an SST and a subsonic transport, Miami - Paris, +6 hours time shift

\section{Flight frequency}

In case there is enough demand for scheduling more than one daily flight on certain routes, passengers will have alternatives to choose from. An increased flight frequency, all else being equal, will generate additional demand ${ }^{6}$.

\section{E. Fleet and network planning}

Even if demand justifies scheduling SST service on a certain route (4 flights a week, for example), this does not at all mean that one aircraft will be acquired for this application. Well-run airlines will only buy planes in case they can utilize them highly, and they will most probably merely consider acquiring whole fleets.

This means that in order to forecast SST market demand more reliably, a fleet and network planning model must be put into use.

\section{F. Length of stay}

The longer a traveller plans to stay at his destination, the less he will require quick transportation. Thus, expected demand could be modulated with the length of stay figures in the final data files.

\section{G. Supersonic overland flight and rerouted flight respectively}

Market estimations need to consider either the expected higher cost of a low-boom SST or the reduced advantage of a ban-constrained SST on specific routes with respect to flight time.

\section{H. Value proposition}

Business class passengers used to roomy cabins, reclining chairs, ample seat pitch, and manifold cabin services will particularly observe the value proposition of an SST flight. Concorde's cabin rather reminded of current regional shuttles with its 4-abreast seating and 34 in $(86 \mathrm{~cm})$ seat pitch; the service was first class, though. 
These conditions will probably be found in future SSTs, too: Supersonic aircraft will necessarily have comparably narrow cabins for aerodynamic efficiency reasons; also, less room for relaxation is thought to be required as flight durations are shorter. Not all passengers will accept this tradeoff on convenience.

\section{SST Market Estimation Methodology}

Reliable models for the factors of influence mentioned in the last chapter have to be developed and included in a more exact, holistic modelling framework for the assessment of the global supersonic airline transportation market.

For now, the following assumptions have been made for an estimation of possible SST sales numbers on the basis of the final business ticket demand data files:

- The point in time considered for the assessment at hand is the year 2025 , which is thought to be a plausible entry of service date for an SST.

- Any future SST operating from civil airports will, in the authors' expectation, have a moderate cruise Mach number between 1.5 and 2 since it will have to meet airport noise certification criteria. As cruise Mach increases, the most efficient engine bypass flow ratio diminishes, causing high jet velocities and high noise at takeoff in consequence. Future stringent noise regulations will require engines with at least moderate bypass ratios which will have lower most efficient cruise speeds. In the following, a Mach number of 1.7 is supposed. (As a side note, the idea of SSTs with more than one type of engines was disregarded for reasons of complexity and operating economy.)

- Routes with flight distances below 3,500 kilometers are not taken into account, as time gain is deemed not significant enough. An SST (Mach 1.7) will take about 2 hours and 20 minutes for said distance, assuming an average speed of about $1,500 \mathrm{~km} /$ hour, while a conventional subsonic aircraft will take about 4 hours and 22 minutes when averaging on $800 \mathrm{~km} /$ hour. 2 hours are assumed to be a plausible threshold regarding time savings.

- The average daily distance flown by an SST (Davg) will be $16,000 \mathrm{~km}$. Assuming a mean speed of 1,600 $\mathrm{km} /$ hour for a Mach 1.7 SST, this would translate into 10 hours net flight time and a yearly utilization of 3650 flight hours which are plausible figures for airliners ${ }^{13}$.

- SST flights will only be scheduled if the demand justifies at least two flights weekly in both directions an outward trip at the beginning of the week and a return trip for the weekend, for instance.

- The passenger load factor $(P L F)$ is set to $75 \%$ which is close to the overall fleet average in established full service network carriers ${ }^{13}$.

- Regarding the market for ban constrained SSTs, only routes allowing for supersonic cruise percentages of $75 \%$ or more are taken into account.

- It can not be predicted yet how many passengers are going to switch to SST service. Thus, we calculate total SST demand for an array of basic passenger switching percentages $(P S P)$, namely $10 \%, 15 \%$, $20 \%, 30 \%, 50 \%$, and $100 \%$. The resulting numbers are modulated using the "variation from expected yield" $(V E Y)$ rate.

Following said parameters, the specific SST need on a route (Nsst) can be calculated with the formula

$$
N s s t=\frac{P y \cdot P S P \cdot(1+V E Y)}{C s s t \cdot P L F \cdot 365} \cdot \frac{D}{D a v g}
$$

where

- $P y \quad$ is the yearly passenger number,

- $P S P$ is the passenger switching percentage,

- $V E Y$ is the variation from the expected yield,

- Csst is the seat capacity of the aircraft considered,

- $P L F$ is the passenger load factor,

- $D$ is the great circle distance between origin and destination, and

- Davg is the average distance flown by an SST in one day.

The total SST aircraft count is calculated by summarizing all figures of Nsst.

\section{SST Market Estimation Results and Discussion}

As mentioned before, the need for SST aircraft was calculated for flat percentages of passengers that switch from premium class to SST service. (The estimation of switching percentages for specific city pairs is going to be assessed in future works on the basis of the factors of influence discussed in Chapter V.)

6

American Institute of Aeronautics and Astronautics 
Figures 6 and 7 depict the SST need with respect to given aircraft capacities and passenger switching percentages, the former figure for the (more realistic) case of present supersonic overland flight bans, the latter one for the case of unrestricted supersonic flight.

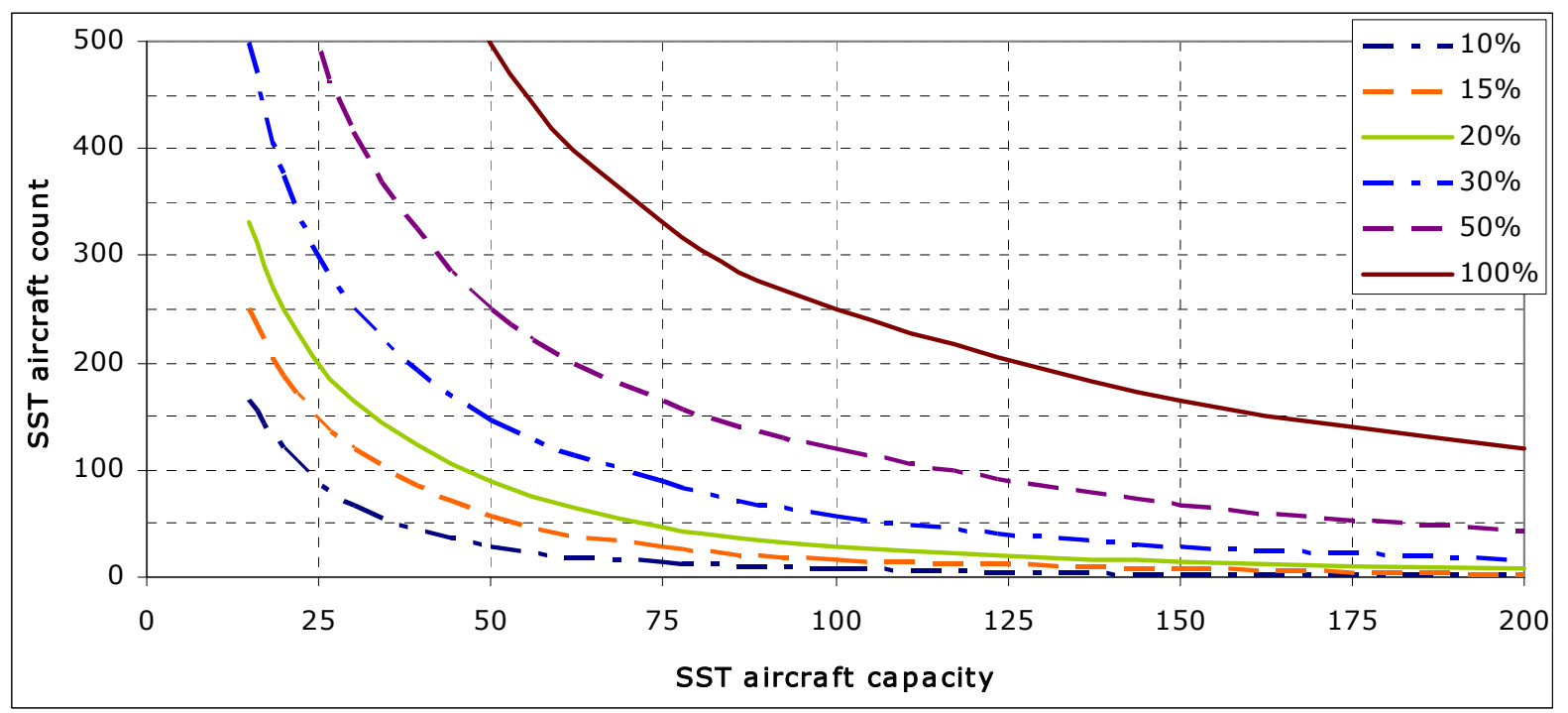

Figure 6. Expected SST demand in 2025 w. r. t. passenger switching percentage; restricted overland flight

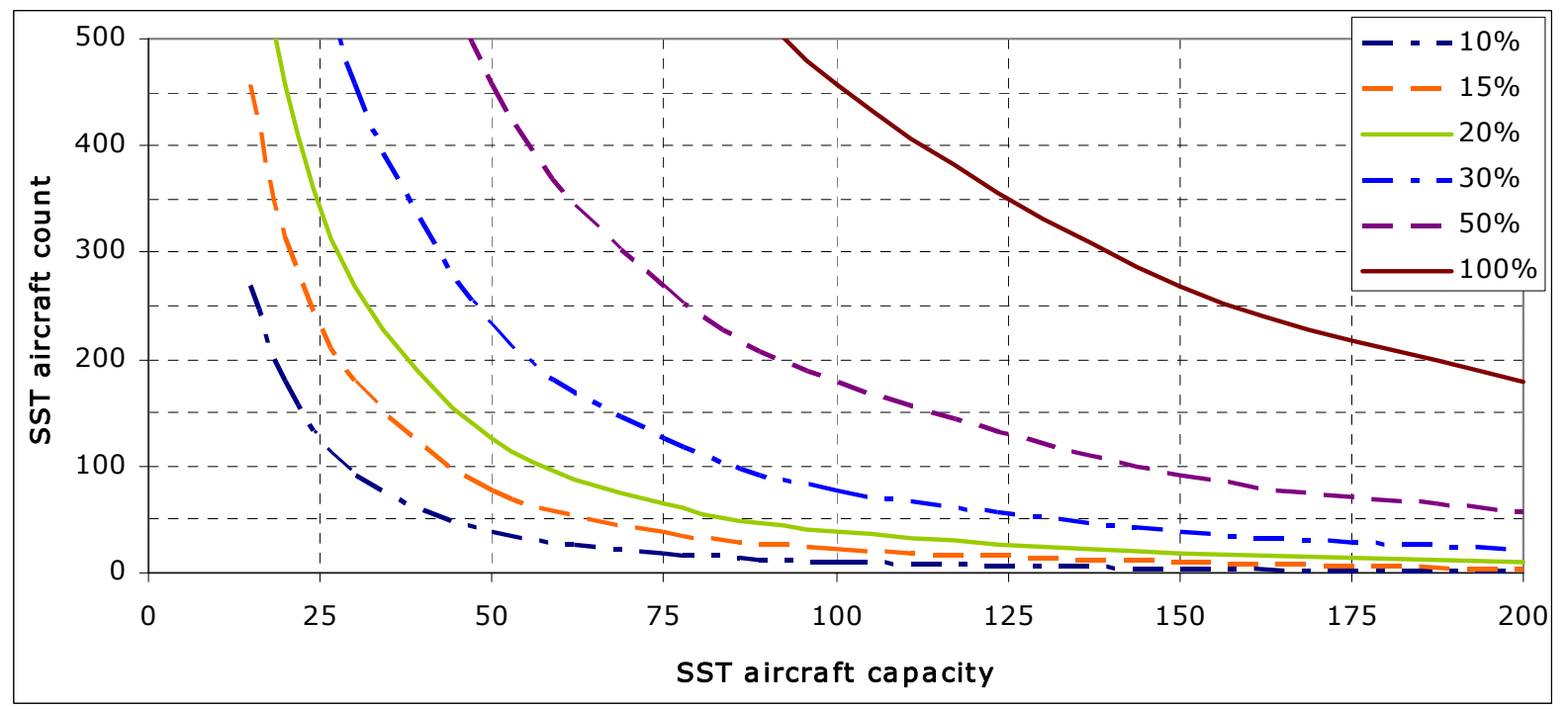

Figure 7. Expected SST demand in 2025 w. r. t. passenger switching percentage; unrestricted overland flight

Firstly, it shows that the market diminishes sharply with increasing passenger capacity of the SST design. This correlation is quite obvious since on the one hand, fewer city pairs will bear enough demand for bigger aircraft, and on the other hand, the total number of passengers can be distributed to fewer SSTs. In reality, the effect will be compensated to a small extent as cost per passenger will be lower with larger aircraft for economy of scale reasons. Nevertheless, the trend shown will most certainly prove valid on the whole.

This generally means that the smaller the SST, the larger its market opportunities will be. A passenger changing percentage of $20 \%$ would assumingly generate a need for about 200 aircraft seating 25 despite restrictive bans (Fig. 6). However, falling below a certain seat count, the cost per passenger will become so high that the total SST need is going to diminish again in reality. There will most definitely be a seat number optimum that bears the highest potential of civil supersonic aircraft sales. Estimating said optimum SST size should be the aim of future research. 
Secondly, we tend to agree with Davies' conclusion ${ }^{5}$ that there has probably never been a market for Concordesize supersonic airliners carrying 100 passengers, let alone for U.S.-type SSTs with $234^{14}$ or even $300^{4}$ seats. Looking at Figure 6 and bearing in mind that large SSTs will most definitely have to supercruise over water exclusively, $100 \%$ of premium passengers on relevant routes would have to switch to SST service in the year 2025 only to enable a market for 250 Concorde-type SSTs. Presuming a set of sometimes unfavorable factors of influence, as discussed in Chapter $\mathrm{V}$, and expecting counter measures regarding price and service level by competing subsonic airlines, one has to step down toward more realistic estimations. $30 \%$ of passengers switching appears to be more verisimilar, resulting in a market of about 60100 -seated SSTs; this can hardly be considered as a justification for an ambitious supersonic aircraft development program.

Thirdly, in case all overland flight bans are lifted, we assume that the global SST market will merely grow by $50 \%$ at best. (Please consider that the SST count above about 200 aircraft in Figure 6 is underestimated because overwater cruise percentages for lower-ranking routes were not available yet.)

Fourthly, a new issue to impact the prospect of supersonic airliners emerged from our studies: It appears to be certain that any supersonic transportation market will have its nucleus in London, UK. In all tested scenarios, London will need to host more than $25 \%$ of all SST aircraft, either as a home base or as a destination. Given a global fleet of 200 arbitrarily sized SSTs, about 60 of them will arrive in London at least once a day, many of them even twice. If coming into service, supersonic airliners will severely aggravate congestion issues at London airports, even more so as they will additionally require preferential dispatch, mostly within the traffic peak hours, in order to keep the airlines' time saving promises.

Fifthly, it is possible to find apt non-stop flight ranges for new SST designs by drawing cumulated SST need relative to city pair distances. Figure 8 shows said relations for the example of 50 -seat-SSTs and a passenger switching percentage of $10 \%$. This is a case with relatively low total demand, but focusing on the market core and particularly differentiating in terms of demand jumps and plateaus (while other cases have found to produce very similar, yet less "jumpy" graphs). In order to capture a maximum of the market with a minimum of flight range, such distances should be considered where the graph runs into a plateau, meaning that there is no instant benefit from an incremental increase regarding range. Examining the graphs, such plateaus can be found at roughly 6640 $\mathrm{km}(3585 \mathrm{~nm}), 7900 \mathrm{~km}(4265 \mathrm{~nm})$, and at $9380 \mathrm{~km}(5065 \mathrm{~nm})$ for boom-restricted SSTs or at $6360 \mathrm{~km}(3435 \mathrm{~nm})$ and $9720 \mathrm{~km}(5250 \mathrm{~nm})$ for low-boom SSTs, respectively. Thus for instance, given a conventional 50-seat SST, $10 \%$ of all premium passengers switching, and a flight range of $3585 \mathrm{~nm}$, about $54 \%$ of the market could be captured with non-stop operations and even $89 \%$ with additional one-stop operations.

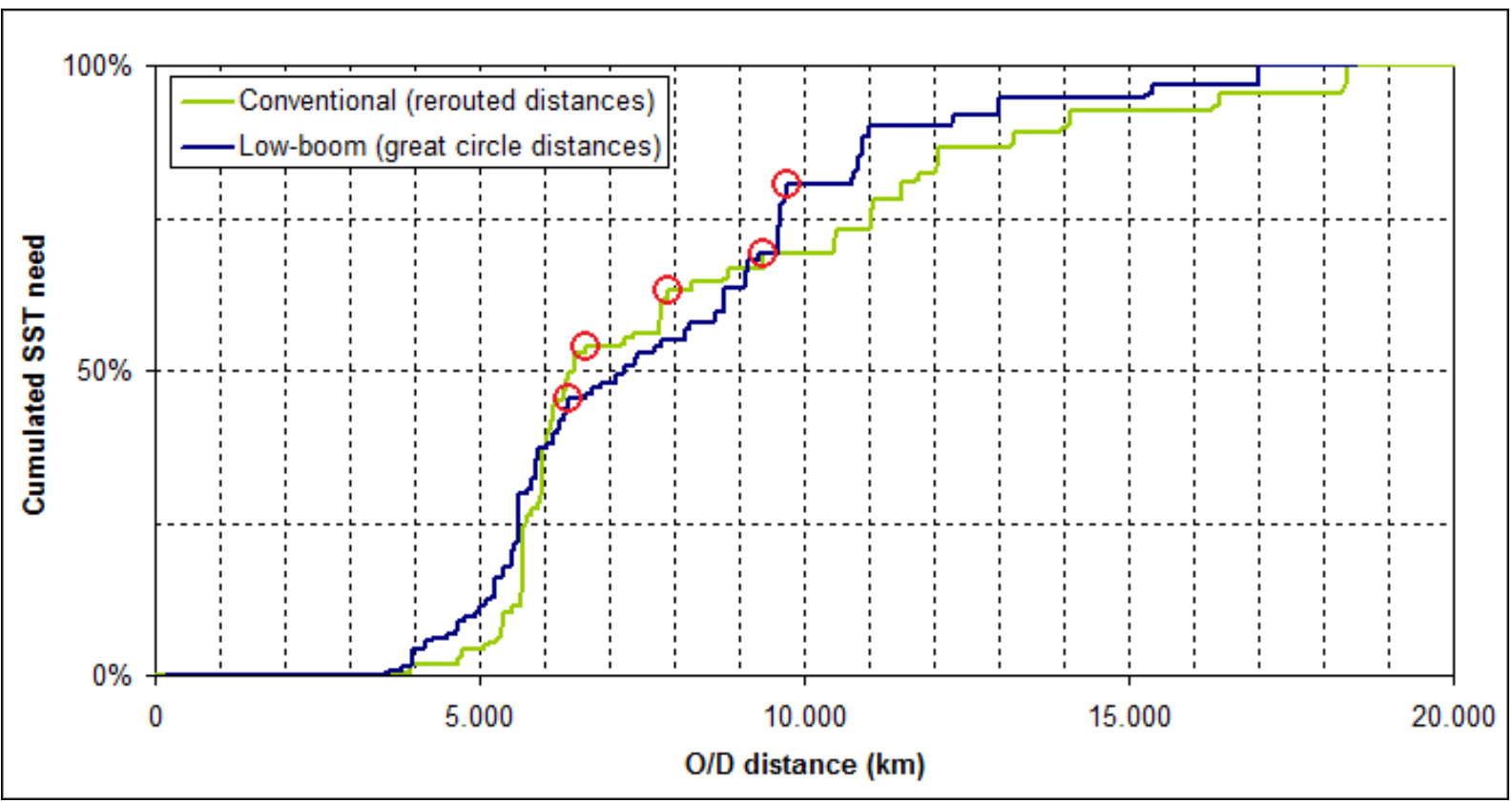

Figure 8. Market capture in terms of cumulated SST need over city pair distance (50 seats, 10\% PSP) 


\section{Recommendations for Future SST Programs}

At last, the authors would like to make some preliminary recommendations for the preferable path toward reentering civil scheduled supersonic flight:

In the short and medium term, new projects should not be based on sonic boom abatement technologies. Research on the topic is showing progress, but there is unforeseeable risk involved regarding technological feasibility, fuel efficiency, legislation, and social acceptance so that these insecurities should not be added to the already highly ambitious enterprise of a civil supersonic aircraft program. Many markets will probably be preservable with the help of smart flight path planning anyway.

Next, plans for large SSTs should be viewed critically, since there will assumedly be only little demand for such airplanes. The thinking needs to turn toward small supersonic airliners carrying about 15 to 25 passengers that require significantly lower development risk and expenditures as well as a much lower market share in order to allow for a successful development program generating profits for all stakeholders.

Moreover, small supersonic planes will open up new market opportunities as they will attract interest from customers envisaging non-scheduled, on-demand operation: High net worth individuals, fractional aircraft companies, corporate flight departments, and government agencies. It is quite possible that the largest market for civil supersonic aircraft in terms of aircraft sales will make use of the combined demand from airlines and from ondemand operators.

Lastly, chances are deemed substantial for a small supersonic aircraft development program to succeed on the civil aviation market, the more so as passenger numbers will likely continue growing in spite of global economic turmoil.

\section{Conclusion}

This work has assessed the future market potential of supersonic airliners, making use of global premium ticket sales figures. It was shown that most likely, there is not enough demand to support large supersonic transport (SST) aircraft with seat numbers in the hundreds. Yet, aircraft sales opportunities were proven to increase with decreasing airplane capacities. Small percentages of passengers willing to change to supersonic service - between $15 \%$ and $30 \%$ - are deemed sufficient to allow for economic success of small SSTs seating roughly 20 passengers, even in (the realistic) case that worldwide overland flight bans for civil supersonic aircraft remain effective.

\section{References}

${ }^{1}$ Lichtfield, J., "London to New York in 90 minutes: is this the Concorde of the future?", The Independent, 20 June 2011, URL: www.independent.co.uk/travel/news-and-advice/2299925.html [cited 8 August 2011]

${ }^{2}$ Butterworth-Hayes, P., "Europe speeds up hypersonics research", Aerospace America, June 2008, pp. 24-28.

${ }^{3}$ Ohnuki, T., Hirako, K., Sakata, K., "National Experimental Supersonic Transport Project", $25^{\text {th }}$ International Congress of the Aeronautical Sciences (ICAS 2006), September 3-8, 2006, Hamburg, Germany.

${ }^{4}$ Anonymous, "High-Speed Civil Transport Study", Boeing Commercial Airplanes, NASA Contractor Report CR-4233, NASA Langley Research Center, Hampton, Virginia, 1989

${ }^{5}$ Davies, R. E. G., "Supersonic (Airliner) Non-Sense - A Case Study in Applied Market Research", Paladwr Press, McLean, Virginia, 1998

${ }^{6}$ Sabre Airline Solutions, Airport Data Intelligence, online database, URL: $\underline{w w w . r o u t e s o n l i n e . c o m / d a t a / s a b r e / ~[c i t e d ~} 8$ August 2011]

${ }^{7} \mathrm{Li}$, W., Shields, E., "Generation of Parametric Equivalent-Area Targets for Design of Low-Boom Supersonic Concepts", AIAA paper 2011-462, 2011

${ }^{8}$ Rallabhandi, S., Mavris, D., “Aircraft Geometry Design and Optimization for Sonic Boom Reduction”, AIAA Journal of Aircraft, Vol. 44, No. 1, pp. 35-47, 2007

${ }^{9}$ Coulouvrat, F., "The Challenges of Defining an Acceptable Sonic Boom Overland", AIAA paper 2009-3384, 2009

${ }^{10}$ Seebass, R., "History and Economics of, and Prospects for, Commercial Supersonic Transport", RTO Education Notes \#4, paper no. 1, November 1998

${ }^{11}$ Anonymous, "Report of Supersonic Task Group of Working Group 1", Committee on Aviation Environmental Protection (CAEP) of the International Civil Aviation Organization (ICAO), Montreal, February 2010,

URL: http://www.obsa.org/Documentos\%20compartidos/CAEP-8-WP-35.pdf [cited 12 August 2011]

${ }^{12}$ Anonymous, "Current Market Outlook 2011-2030", Boeing Commercial Airplanes - Market Analysis, June 2011, URL: www.boeing.com/commercial/cmo/pdf/Boeing_Current_Market_Outlook_2011_to_2030.pdf [cited 8 August 2011]

${ }^{13}$ Belobaba, B., Odoni, A., Barnhart, C. (editors), "The Global Airline Industry", John Wiley \& Sons, Ltd, Chichester, UK, 2009

${ }^{14}$ Anonymous, “Boeing's Latest SST Proposal”, Flight International, Vol. 95, No. 3 pp. 104-108 and No. 4 pp. 133-136, Iliffe Transport Publications Ltd, London, UK, 1969 